\title{
Urgences
}

\section{Ghislain Bérubé, Des ires réelles, Rimouski, Éditions Passages, 1982, 96 p.}

\section{Jean-Marc Cormier}

Numéro 6, 4e trimestre 1982

URI : https://id.erudit.org/iderudit/025096ar

DOI : https://doi.org/10.7202/025096ar

Aller au sommaire du numéro

Éditeur(s)

Urgences

ISSN

0226-9554 (imprimé)

1927-3924 (numérique)

Découvrir la revue

Citer ce compte rendu

Cormier, J.-M. (1982). Compte rendu de [Ghislain Bérubé, Des ires réelles,

Rimouski, Éditions Passages, 1982, 96 p.] Urgences, (6), 90-92.

https://doi.org/10.7202/025096ar

Ce document est protégé par la loi sur le droit d'auteur. L'utilisation des services d'Érudit (y compris la reproduction) est assujettie à sa politique d'utilisation que vous pouvez consulter en ligne.

https://apropos.erudit.org/fr/usagers/politique-dutilisation/
Cet article est diffusé et préservé par Érudit.

Érudit est un consortium interuniversitaire sans but lucratif composé de l'Université de Montréal, l'Université Laval et l'Université du Québec à Montréal. Il a pour mission la promotion et la valorisation de la recherche. https://www.erudit.org/fr/ 
Ce que Francine Carrier a cherché, dans son roman, c'est d'abord à s'identifier aux personnages obscurs, à ceux dont l'actualité de l'époque n'a pas parlé. Elle a pris sur elle d'inventer et de préciser leurs émotions.

Documentée, l'auteure cache ses connaissances au profit d'une intrigue qu'elle tend à rendre la plus sympathique possible. Dommage. Car les détails historiques, existants, se fondent dans un langage dont on retient surtout la facilité d'écriture et les multiples clichés qu'on ne peut taire.

"Mille cris dans la nuit", ces cris de désespoir poussés par les rescapés et par ceux qui ont péri dans le naufrage de l'Empress, si détaillés soient-ils, convainquent mal. Auréolés d'une vision voulue trop humaine.

Ce n'est pas l'intention, c'est donc le traitement qui fait de ce livre, qui se lit bien, une tentative discutable. Peut-être parce que tout phénomène historique, à moins d'une habileté sans borne, ne se prête pas à une interprétation romancée...

Hélène Chassé

DES IRES RÉELLES, poèmes de Ghislain Bérubé, 96 pages. IIlustrations de Dorys Tremblay. Éditions Passages, Rimouski, 1982.

Ce premier ouvrage de Ghislain Bérubé est divisé en cinq parties (Des ires d'en dedans, Des ires d'en dehors, Désirs, Ires funambulesques et Désirs voyageurs) mais il conserve tout au long une unité de ton que peu de nouveaux poètes possèdent en propre.

Identifié au funambule, le poète (comme d'ailleurs le commun des mortels dont il est) aura traversé sur la corde raide, et avec une certaine prestance malgré les pièges de la réalité et ceux de la littérature, ses propres colères intérieures provoquées par un environnement humain qu'il aura perçu comme factice: "être en 
émoi devant corps simulacre" (p. 11), ou simplement par le désespoir pesant des hommes: "les corps gisent/ comme pour répondre à la poésie" (p. 14), "sur la rue des cadavres déambulent"' (p. 18).

Puisque les circonstances sont aliénantes, il en aura fait la preuve dans ses "ires d'en dedans", il tentera de "programmer une révolte" (p. 24) à la recherche du jour où "dans la bouche des hommes/le langage renouvelé de l'amour/ communiera avec les sensations" (p. 28). II rappellera que "les poètes sont acides/ quand ils parlent de société"' (p. 23) et souhaitera que l'arcen-ciel se tende enfin "pour briser la glace de nos lacs d'égocentrisme" (p. 35).

Le lecteur ressentira sans doute le profond désir de victoire sur le mal que véhicule ce jeune auteur tout aussi bien que sa quête d'amour absolu doublée d'une espèce de grande peur que toute la réalité soit truquée: "pourquoi tout ce temps/ pour saisir un brin d'étincelle plus incandescent/ que le dernier paroxysme où je divague" (p. 42) mais "elle s'en vient/ elle sort des rivages nocturnes" (p. 42) "un soir de bal chez Boulé/ une pleine lune est entrée en moi/ comme une balle de mitraille perdue" (p. 52).

Donc, même si le poète/funambule frémit parfois "à l'étreinte du nocturne infernal" (p. 53), il s'apprête à "vivre une aventure plus vraie/ qu'avec les charlatans du plaisir" (p. 58) et son "vouloir voler plus loin que la réalité imposée/ avec des sourires donnés au coin des tables" (p. 58) n'a d'égal que son attachement pour "ceux et celles qui trempent/ leurs lèvres à ce mini festin/ de l'amour entretenu avoué" (p. 60).

Plusieurs lecteurs endosseront pour leur propre compte ses dénonciations de l'urbanité planifiée par les pouvoirs d'argent dans leur course folle au progrès naïf et cupide puisque, comme le funambule, ils pensent déjà que "dans ce cube superficiel/ la chair humaine n'est qu'un bonbon/ qui adoucit le labeur d'une journée" (p. 67), parce qu'ils savent bien que, trop souvent, "une bandaison bien courte en mémoire/ on se dirige à I'hôtel le plus proche" (p. 68) pour "caresser coup sur coup/ le goulot de six grosses bières prises par dépit" (p. 68). 
Dans un vers bouleversant de simplicité et de vérité, le funambule nous aura fait découvrir que "chaque regard triste EST UN PAS VERS LA MORT" (p. 74) avant de nous crier "j'aime encore la crise cardiaque d'amour" (p. 75). II fermera la suite poétique "Des ires réelles" avec "Désirs voyageurs", où il révèle entre autre un attachement palpable pour Fort-Rupert et la population autochtone de cette région où il a travaillé ces dernières années.

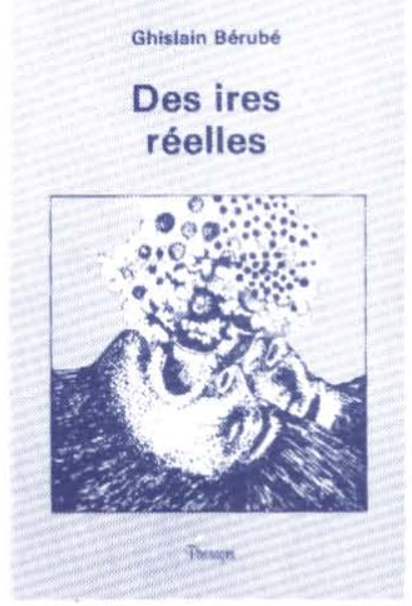

Malgré certaines abstractions peu évocatrices et peu utiles à son intention de base, le livre de Ghislain Bérubé révèle dès la première lecture une âme riche et féconde empreinte d'un immense amour des petites gens, d'un certain sens critique du désoeuvrement et d'une juste révolte dirigée contre ceux qui détiennent les rênes du pouvoir sans profiter de leur situation de privilégiés pour adoucir les peines de l'humanité.

II s'agit d'un livre aussi intimiste que social et, si son riche contenu ne peut manquer de faire vibrer les cordes sensibles qu'il nous reste, les quatorze belles illustrations de Dorys Tremblay et l'édition soignée de cet ouvrage ajoutent encore au plaisir du lecteur. 